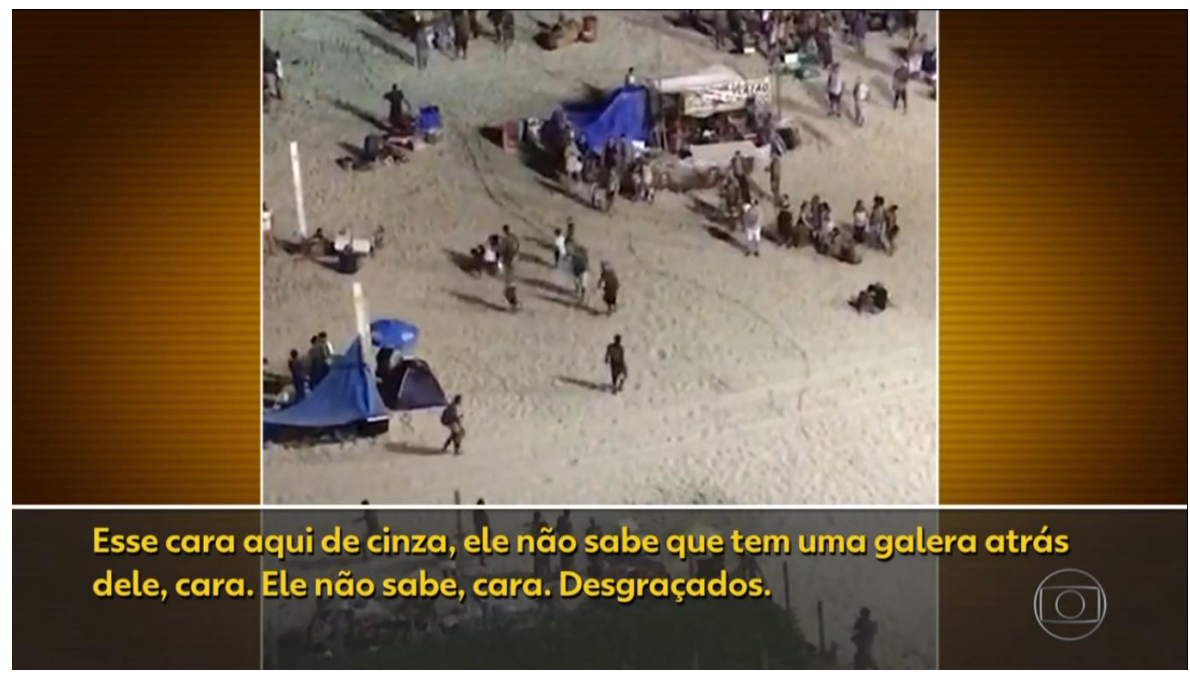

\title{
A violência urbana nas narrativas de telejornais e a construção do inimigo
}

Urban violence in television news stories and the construction of the enemy

Graziele Rodrigues de Oliveira ${ }^{1}$

ORCID https://orcid.org/0000-0002-6034-5401

\begin{abstract}
Resumo:
$\mathrm{O}$ artigo reflete sobre o legado colonialista no Brasil e o apagamento das questões sociais nas narrativas de telejornais sobre violência urbana. No Brasil a criminalidade é tratada pelo Estado de forma emergencial e se revela como artifício para o controle social e punição aos mais pobres (FOUCAULT, [1987] 2009). Para tanto, foram selecionados dois materiais de telejornais da Rede Globo sobre arrastões em áreas nobres da cidade do Rio de Janeiro. A metodologia de análise consiste na intersecção entre a perspectiva bourdiana e foucaultiana, com base na ideia de que a reprodução do discurso dominante no tempo-espaço naturaliza o problema da marginalização social. As considerações finais desta análise apontam para a atuação dos telejornais na promoção do ódio e na construção do Outro como inimigo.
\end{abstract}

Palavras-chave: Telejornal; Imprensa; Ódio; Violência urbana.

\begin{abstract}
:
The article reflects on the colonial legacy in Brazil and the erasure of social issues in the televised narratives about urban violence. In Brazil, crime is treated by the State in an emergency and is revealed as an artifice for social control and punishment of the poorest (FOUCAULT, [1987] 2009). In order to do so, two Globo TV news materials on trawlers in noble areas of the city of Rio de Janeiro were selected. The methodology of analysis consists of the intersection between the Bourdian and Foucaultian perspectives, based on the idea that the reproduction of dominant discourse in space-time naturalizes the problem of social marginalization. The final considerations of this analysis point to the action of the news programs in the promotion of hate and in the construction of the Other as an enemy.
\end{abstract}

Keywords: Television news; Press; Hate; Urban violence.

\footnotetext{
1 Mestranda em Literatura Comparada pela Universidade Federal da Integração Latino-Americana (UNILA). Especialista em Geopolítica e Relações Internacionais pela Rede de Educação Claretiano. Graduada em Comunicação Social - Jornalismo pela União Educacional de Cascavel (Univel-2015) e Comunicação Social - Publicidade e Propaganda pelo Centro de Ensino Superior de Maringá (Unicesumar2010). E-mail: grazielecomz@gmail.com
} 


\section{Introdução - A violência como resultado do Brasil colonial}

No Brasil, a criminalidade é tratada pelo Estado de forma emergencial e se revela como artifício para o controle social e punição das classes populares. A violência e o caos midiatizados na sociedade contemporânea brasileira escondem quase 400 anos de Brasil escravocrata e pouco mais de 100 anos de um processo abolicionista sem amparo social.

O autor Michel Foucault no livro Vigiar e Punir ([1987] 2009) destaca os mecanismos de poder que envolvem a justiça criminal como uma das esferas que atua na sociedade, não como forma de defesa, mas como modelo disciplinar. Foucault, neste livro, faz um levantamento sobre a história da punição e as mudanças de sentido do conceito de punição no tempo-espaço. Assim, seu pensamento é chave de leitura para se refletir sobre as narrativas de telejornais que reproduzem discursos consonantes com o modelo disciplinar da punição no "combate" à violência urbana.

Historicamente, entende-se que a violência urbana no Brasil passa a ser uma problemática acentuada resultante do abandono social a partir da política do ventre livre ${ }^{2}$, desta forma, a violência urbana no Brasil advém, dentre outros fatores, de um legado colonial e de um processo de apagamento da resistência negra (SOUZA, 2017).

Destinadas às margens, as pessoas negras, no passado escravizadas e "libertas" a partir da assinatura de um documento que não lhe concedeu garantias ou reparação, se viram tendo que exercer os trabalhos mais degradantes num mercado competitivo e sem terra para morar ou trabalhar. Desde então, a sobrevivência de populações negras depende não só da luta econômica e política, mas também pela inserção num sistema capitalista regido pela dominação europeia, com cultura e ideologia diferentes. Assim, o olhar para o negro é do "outro", pois a sua religião era/é outra, seus costumes eram/são outros e principalmente a ideia de cor da pele como fator preponderante da dominação e de diferenciação dos "iguais". O racismo é motivo influente na divisão das classes sociais no Brasil, a sociedade é estruturada não só pelo fator econômico, mas a causa da pobreza parte do processo violento da colonização, como trata Florestan Fernandes no livro $A$

\footnotetext{
${ }^{2}$ Lei promulgada em 28 de setembro de 1871, a qual determinava que os filhos de mulheres negras escravizadas fossem livres a partir da maioridade (na época 21 anos). Até esta idade (21 anos) o filho da pessoa escravizada ficaria sob a tutela do Senhor de sua mãe ou do Estado, decisão que cabia, exclusivamente, ao proprietário da mãe. Lei2040/71. Acesso em: < http://legis.senado.leg.br/legislacao/ListaTextoSigen.action?norma=543813\&id=14382459\&idBinario=15 631093\&mime=application/rtf $>$.
} 
Integração do Negro na Sociedade de Classes, que publicado em 1978, continua sendo referência importante ao tratar da situação do negro no Brasil.

O esquecimento e apagamento da gênese de um país escravocrata são componentes para a naturalização da desigualdade social. Também no livro de Vera Malaguti Batista, $O$ medo na cidade do Rio de Janeiro: dois tempos de uma história, a autora explica que os medos da classe média/alta da cidade do Rio de Janeiro faziam parte do cotidiano burguês desde a colonização: os senhores de escravos carregavam o medo da vingança do negro escravizado e enxergavam nas ruas o perigo iminente do “outro". A revolta das pessoas escravizadas, como a chamada Revolta dos Malês ${ }^{3}$ em Salvador, era tratada pelos jornais da época como uma rebelião por criminosos perigosos. A Revolta dos Malês gerou repercussão internacional e suscitou outras revoltas no país, e, em resposta, na cidade do Rio de Janeiro, passou-se a ser exigido um passaporte para circular pela cidade: a ideia era de evitar as fugas das pessoas escravizadas, que nos séculos XVIII e XIX se intensificaram (BATISTA, 2003). Já nesse tempo, afinal, o jornalismo era pautado pela preocupação econômica, espelhando em páginas de jornal os medos da elite que era sua consumidora e financiadora. Optava-se pela narrativa do caos em detrimento da luta política de libertação.

Assim, o objetivo deste artigo é analisar as narrativas de dois materiais de telejornais da Rede Globo a fim de identificar a manutenção da reprodução dos discursos hegemônicos nas narrativas sobre a violência urbana, e detectar as repetições de sentidos discursivos que legitimam os valores dominantes, portanto, que contribuem para a manutenção das desigualdades sociais e raciais.

O jornalismo que recorto para estes estudos é aquele que carrega o valor simbólico da "verdade"; por isso a escolha dos materiais da Rede Globo é proposital, pela presunção de verdade de que é detentora, pelo caráter discursivo menos evidente quanto à parcialidade da informação se comparado ao telejornalismo de segmento policial ${ }^{4}$, como a especificação de Jessé de Souza sobre o conteúdo do veículo:

\footnotetext{
${ }^{3}$ A Revolta dos Malês aconteceu no dia 25 de janeiro de 1835 em Salvador na Bahia. Os malês eram negros escravizados de religião muçulmana. A revolta era muito temida pelos senhores de escravos visto que os malês sabiam ler e escrever, o que facilitaria uma organização estratégica.

${ }^{4}$ Telejornalismo de segmento policial: o jornalismo tido como "não legítimo", àquele que se refere aos programas televisivos de notícias, como por exemplo, Cidade Alerta (Rede Record), Brasil Urgente (Rede Bandeirantes), etc.
} 
[...] a Globo também se especializou em veicular a farsa maior do capitalismo financeiro em escala mundial: esconder a superexploração do trabalho que ele implica [...]. Assim a defesa de minorias, desde que não envolvam repartição de riqueza e poder social, é apoiada pela empresa, que pode posar de crítica e emancipadora. A glorificação da periferia das grandes cidades, desde que não envolva real incorporação das classes populares aos bens civilizatórios, o que exigiria a discussão de suas carências que são reais, também são defendidas pela Globo. (2017, p. 120).

Para tanto a violência urbana será analisada a partir de duas principais perspectivas: a teoria de Michel Foucault, ao evidenciar a justiça criminal como instrumento de poder, pois para o autor, as narrativas sobre a violência urbana nos jornais promovem a aceitabilidade de outras violências, como a violência Estatal e econômica (poder gerador das desigualdades sociais - fome, desemprego, cerceamento de direitos fundamentais à dignidade humana -); e a literatura sociológica de Pierre Bourdieu, sobre o poder simbólico e os efeitos discursivos da televisão.

\section{Alguns números: a justiça criminal e a marginalização das classes populares}

Ao tratar de estatísticas, é possível relacionar as teorias de Bourdieu e Fernandes - sobre a estruturação da sociedade com base no capital econômico, cultural e simbólico com a situação socioeconômica no Brasil ligada à questão do racismo: dados divulgados pelo Instituto Brasileiro de Geografia e Estatística (IBGE) revelam que as populações negras e pardas têm menores salários se comparados às populações brancas. $\mathrm{O}$ resultado obtido no último trimestre de 2016 estima uma renda média mensal de $\mathrm{R} \$ 2.660,00$ para as populações brancas, $\mathrm{R} \$ 1.480,00$ para as populações pardas e $\mathrm{R} \$ 1.461,00$ para as populações negras.

Desta forma, ao relacionar a questão socioeconômica com a população carcerária no Brasil, é possível destacar em números que mais do que uma questão de classe, a questão étnico-racial é um dos instrumentos para a dominação e que corroboram para a marginalização da classe popular. Segundo dados do Infoben (Levantamento Nacional de Informações Penitenciárias) de 2016, a população carcerária teve um aumento de $707 \%$ em 2016 se comparado aos anos 1990. No total são 726.712 pessoas presas, dentre as quais, $64 \%$ são negras, $35 \%$ são brancas e $1 \%$ são amarelas. Os dados ainda mostram que o nível de escolaridade resulta em $4 \%$ de analfabetos, $6 \%$ alfabetizados sem curso regular, $51 \%$ possuem o ensino fundamental incompleto, $14 \%$ fundamental completo, $15 \%$ ensino 
médio incompleto, $1 \%$ com ensino superior incompleto e não pontuaram com ensino superior completo, sendo possível identificar a influência da baixa escolaridade com a marginalização.

Também é nítido o problema da marginalidade intrinsecamente ligado a fatores econômicos, vê-se pelo percentual da violência urbana de ordem econômica no Brasil ${ }^{5}$ : sendo $26 \%$ dos casos relacionados ao tráfico, $26 \%$ ao roubo, $12 \%$ ao furto, $5 \%$ ao desarmamento, $2 \%$ a formação de quadrilha, $3 \%$ latrocínio, $3 \%$ receptação, restando $23 \%$ das demais infrações não ligadas diretamente à questão econômica. $\mathrm{O}$ alto percentual das práticas de violência urbana de fins econômicos revela uma situação de conflito provocado por uma sociedade desigual, ao passo que os discursos persuasivos da mídia justificam a repressão policial e apaga a gênese destes conflitos tomando como medida de segurança a policialização:

[A] notícia policial, por sua redundância cotidiana, torna aceitável o conjunto dos controles judiciários e policiais que vigiam a sociedade; conta dia a dia uma espécie de batalha interna contra o inimigo sem rosto; nessa guerra, constitui o boletim cotidiano de alarme ou de vitória. (FOUCAULT, 1997, p. 251)

Vale ressaltar que para Foucault (2009) o sistema da justiça criminal (sistema policial, sistema penal) está pautado nas relações de poder e no modelo disciplinar que este representa, ou seja, a pena exercida sobre o criminoso a partir do século XIX até hoje, não tem como objetivo o ato infracional, mas servir de exemplo (mostrar que o crime não compensa). Nas palavras de Foucault a função da justiça criminal é "dar aos mecanismos da punição legal um poder justificável não mais simplesmente sobre as infrações, mas sobre os indivíduos; não mais sobre o que eles fizeram, mas sobre aquilo que eles são, serão, ou possam ser" (FOUCAULT, 2009, p. 22, grifo meu). Desta forma, “o conhecimento do criminoso, a apreciação que dele se faz, o que se pode saber sobre suas relações entre ele, seu passado e o crime, e o que se pode esperar dele no futuro (FOUCAULT, 2009, p. 22, grifo meu). Neste sentido, a justiça criminal é política/ideológica no que tange a servir de mecanismo para aprisionar (segregar) o indesejável, o que é pobre e que não compartilha dos mesmos códigos de conduta

\footnotetext{
${ }^{5}$ Os dados são do Levantamento Nacional de Informações Penitenciárias: BRASIL. MINISTÉRIO DA JUSTIÇA. Levantamento Nacional de informações Penitenciárias. Brasil: 2016. Disponível em: http://www.justica.gov.br/news/ha-726-712-pessoas-presas-no-brasil/relatorio_2016_junho.pdf. Acesso em: 30 jul. 2018
} 
dominante. Assim, se detecta um conjunto de sistemas de classificações (traços distintivos que associam a classe social dos sujeitos ao seu estilo de vida - habitus -) emitido sobre o Outro como argumento punitivo (BOURDIEU, 1989). Evidencio com base em Bourdieu (1989), uma rede de ideias, padrões, crenças e valores que, mediante a atuação de poderes simbólicos (aqui exemplificado pela atuação do telejornalismo) é naturalizada no cotidiano da sociedade, mascarando e invisibilizando violências objetivas e/ou simbólicas - praticadas nas mais diferentes esferas. Os mascaramentos de dada situação social em relação à marginalização da classe popular, fazem parte de uma rede simbólica que, além de estruturar a sociedade em classes, ainda inibe a ascensão dos agentes na hierarquia social. $\mathrm{O}$ autor elenca o capital cultural e simbólico ao conhecimento dominante como sensibilizadores dos valores e crenças dos indivíduos: valores não condizentes com o que é dominante tendem a ativar processos de exclusão contra quem os têm, nas palavras de Bourdieu:

É assim que os sistemas simbólicos cumprem a sua função política de instrumentos de imposição ou de legitimação da dominação, que contribuem para assegurar a dominação de uma classe sobre a outra (violência simbólica) dando o reforço da sua própria força às relações de força que as fundamentam e contribuindo assim, segundo a expressão de Weber, para a domesticação dos dominados (1989, p. 11).

Desta forma, a posição social dos agentes representa o poder de apropriação dos recursos sociais e urbanos estabelecendo relações assimétricas entre os grupos e se concretizando com as segregações dos espaços da cidade. A paranoia ${ }^{6}$ da proteção da propriedade privada juntamente com os estigmas criados sobre o Outro, formam uma luta de classes no sentido literal da palavra, uma "guerra entre classes". O Outro, o excluído, não só é visto como inimigo, mas a sua idealização como inimigo sai do imaginário social para se concretizar nos constantes atos violentos, seja na violência física dos marginalizados sobre os dominantes, com roubos e assaltos constantes, seja na violência simbólica do Estado e da sociedade hegemônica contra os marginalizados, como o desemprego, o sucateamento das escolas públicas, os salários miseráveis, a percepção

\footnotetext{
${ }^{6} \mathrm{O}$ termo da psiquiatria é aqui utilizado para se referir ao comportamento obsessivo de desconfiança e medo da classe dominante que tem como base os estudos do filósofo Vladimir Safatle: "[...] por sua vez, deve se alimentar da elevação do medo o afeto central do vínculo político (medo da despossessão de meus bens, medo da morte violenta, medo da invasão de minha privacidade, etc.” (2012, p. 77). SAFATLE, Vladimir, Grande Hotel Abismo: Por uma Reconstrução da Teoria do Reconhecimento, São Paulo, Editora WMF Martins Fontes, 2012, 338 p.
} 
social dos corpos (o racismo, a padronização estética do que é belo), a naturalização da pobreza, e a violência física com a repressão da justiça criminal nas suas várias facetas.

\section{Jornalismo televisivo e a construção da identidade cultural do Outro como inimigo}

Para Souza (2009) apesar do passado colonialista no Brasil ser um ponto de partida para entender as desigualdades sociais no país, a sociedade contemporânea se estrutura cotidianamente com outros tipos de violências que vão além de questões econômicas e dos processos escravizantes da história. A mídia tem papel fundamental na construção da ideia do que é o Outro, o "inimigo". Há que se entender como o medo da violência urbana é orquestrado e contado a partir do ponto de vista de "um" (classe dominante) e não do "outro" (dominados). O medo narrado nos jornais é dos dominantes, assim como no período colonial a posição dos jornais revelavam um lado do medo, o medo do "eu" em relação ao "outro", aquele que é o "intruso", que "invadiu” um território no qual não é bem-vindo; a presença do outro só deixa de ser uma ameaça quando é força de trabalho para a classe dominante, ainda que sua circulação nos espaços seja limitada e desconfiada. Assim, as narrativas dos jornais atravessam o tempo-espaço e perpetuam um imaginário em que o Outro é visto como inimigo. Ainda que a marginalidade seja real e crescente, entende-se que os efeitos discursivos das narrativas de jornal contribuem para a marginalização e para o fomento da estruturação da sociedade determinada pelas questões econômicas, sociais e culturais (SOUZA, 2017).

Os efeitos discursivos das narrativas de telejornais sobre a violência urbana contribuem para a criminalização da pobreza e para o racismo. Para Bourdieu (1997) o poder simbólico da televisão está no "ocultar mostrando" (p. 24), como a televisão busca o sensacional, a culpabilidade de um grupo veiculado na televisão gera uma série de mobilizações sociais no incentivo à cobrança punitiva em detrimento de políticas públicas de socialização/ressocialização. É o que Bourdieu (1997) chama de violência simbólica, que ignora/apaga uma realidade social e mostra a problemática da violência de maneira isolada de todas as questões que a geram, nas palavras do autor:

As variedades, os incidentes ou os acidentes cotidianos podem estar carregados de implicações políticas, éticas e etc. capazes de 
desencadear sentimentos fortes, frequentemente negativos, como o racismo, a xenofobia, o medo-ódio do estrangeiro e a simples narração, o fato de relatar, to record, como repórter, implica sempre uma construção da realidade capaz de exercer efeitos sociais de mobilização (ou de desmobilização). (1997, p. 28, grifo do autor).

Por meio da seletividade da notícia, é possível mostrar determinado fato e ignorar outro, e é neste jogo de seletividade que a imagem do "outro" (o marginalizado) é construída por uma rede de significados que estigmatiza o perfil de "criminoso" por um lado, e por outro apaga as questões sociais que o fez se envolver no crime, " $O s$ jornalistas têm 'óculos' especiais a partir dos quais veem certas coisas e não outras; e veem de certa maneira as coisas que veem. Eles operam uma seleção e uma construção do que é selecionado" (BOURDIEU, 1997 p. 25, grifo do autor).

Com vistas a demonstrar a validade desta argumentação, primeiramente uma breve análise crítica da produção da sensação de insegurança, cotejada com os processos socioespaciais de produção do espaço urbano, será relacionada às ideias de Bourdieu (1997) a

respeito da produção de redes simbólicas naturalizadoras e perpetuadoras de discursos dominantes.

\section{Análise das narrativas sobre a violência urbana em telejornais}

A seguir trago para análise os seguintes objetos: uma reportagem do telejornal Bom dia Brasil da TV Globo sobre arrastões na cidade do Rio de Janeiro, e um link ${ }^{7}$ do telejornal Bom dia RJ. Os objetos são parâmetros para compreender como ocorre a construção do medo e do inimigo na cidade. Trecho da Reportagem $1^{8}$ :

- Apresentadora: Olha eu gostaria muito de começar o Bom dia Brasil falando da alegria do carnaval, mas infelizmente a violência no Rio de Janeiro nos obriga a abrir essa edição falando da falta de segurança. Nas últimas horas nossas equipes flagraram vários casos de arrastões na Zona Sul da cidade e na região metropolitana [...].

Entrevistada: Vieram... tipo, cinquenta meninos e arrancaram minhas pulseiras $[\ldots]$.

\footnotetext{
${ }^{7}$ Link é um conceito utilizado dentro do jornalismo televisivo em que o repórter entra ao vivo com informações, fora do estúdio. A fala do repórter pode ser intercalada com imagens ou não. No caso exposto teve apresentação de imagens enquanto o repórter transmitia as informações.

${ }^{8}$ Matéria veiculada na véspera de Carnaval no telejornal Bom dia Brasil do dia 12 de fevereiro de 2018, transposta para o portal de notícias G1 da globo.com.
} 
00:00:32 Repórter: O desespero desta turista de Brasília reflete apenas mais um caso de violência no Carnaval no Rio. Eram cinco da manhã quando ela e um grupo de amigos foram cercados por marginais na Avenida Vieira Souto, um dos endereços mais nobres da Zona Sul do Rio [...].

00:04:25 Apresentadora: Olha a gente questionou a polícia militar sobre estes arrastões de ontem à noite e desta madrugada na Avenida Vieira Souto, ali na praia Ipanema, mas ainda não tivemos nenhuma resposta. Sobre o arrastão de sábado a polícia disse que prendeu um dos criminosos e que apreendeu dois menores, em relação ao arrastão em Niterói a informação é ainda pior, a polícia disse que nem tinha conhecimento de ocorrências ali na região. (BOM DIA BRASIL, 2017, grifo meu).

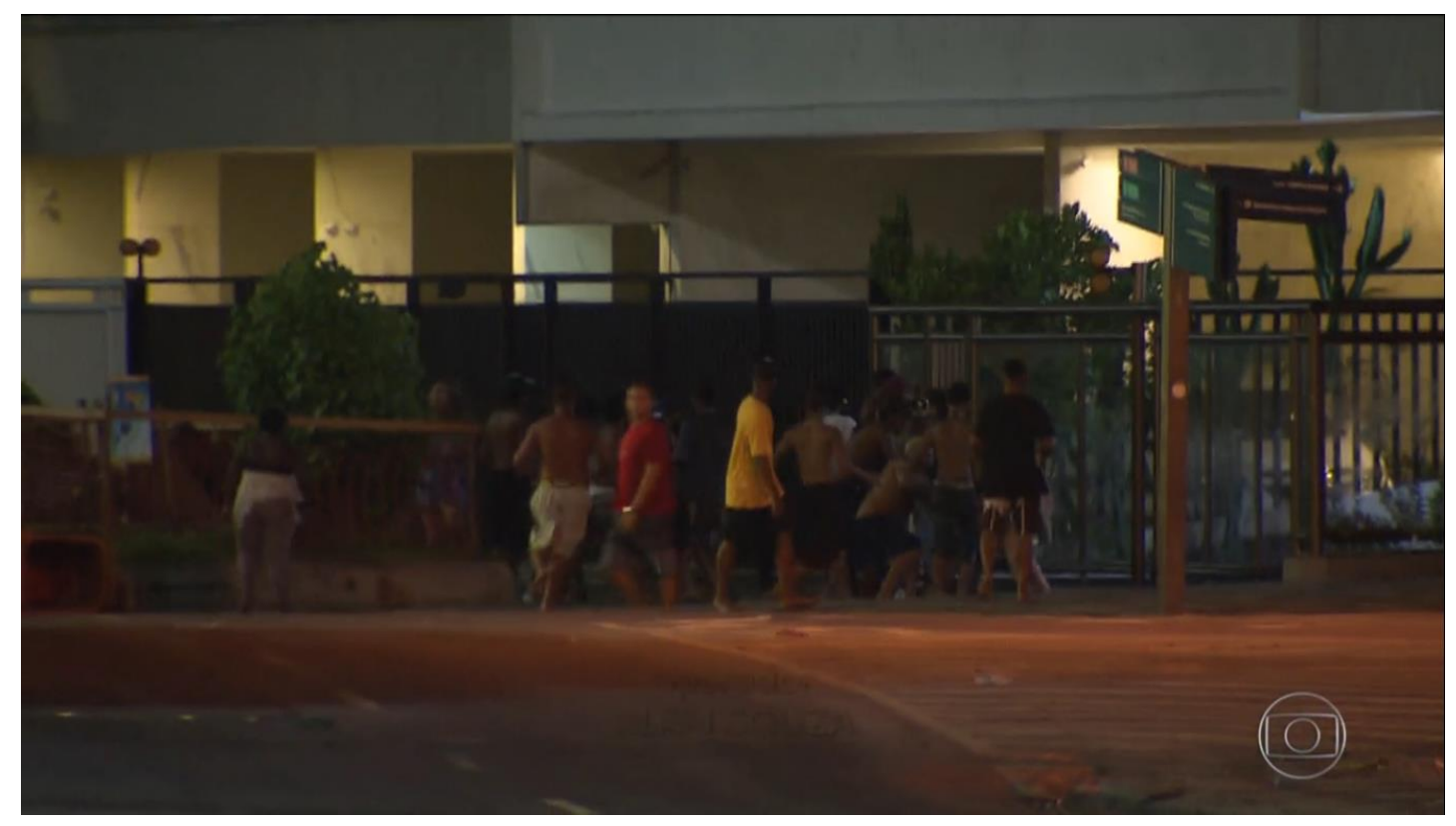

Figura 1- Frame da matéria intitulada: Turistas são vítimas de arrastão em frente a um dos hotéis mais luxuosos do Rio Fonte: G1 PORTAL DE NOTÍCIAS (2018)

Durante a reportagem o texto (off) da repórter era intercalado com imagens de jovens negros e pardos correndo em grupo para cima das turistas. Assustadas, as turistas choravam e pediam a presença dos repórteres como proteção. A primeira reflexão a ser feita no discurso é a ênfase da repórter quanto a: "endereços mais nobres da Zona Sul do Rio" deixando claro que a região é da elite e a onda de violência conseguiu quebrar a fronteira da periferia para a região nobre, o que reflete o conflito entre as classes, mas que também tem cor, duas turistas brancas sendo assaltadas por um grupo de pessoas pardas e negras. As imagens da situação desesperadora das turistas e do grupo que as assaltou, somadas ao texto da repórter em "um grupo de amigos foram cercados por marginais" marcam o olhar para o Outro e definem as características do "inimigo", acentuando os 
estigmas sobre a classe popular. Chama a atenção as palavras, desespero, grupos de amigos versus marginais, tendo como efeito de sentido a culpabilização da ausência de paz sobre um grupo de jovens infratores, inclusive, com menores de idade. De um lado, um grupo de "marginais"; de outro, um grupo de pessoas da classe alta acuado. Assim, há no mínimo duas problemáticas a serem colocadas em pauta: a da violência urbana em si, que a reportagem mostra; e as violências simbólicas a que o grupo de infratores estão submetidos. Porém é predominante o discurso do medo da despossessão de bens da classe alta. Conforme Foucault (2009), o modelo disciplinar da sociedade capitalista intenta a correção pela punição (prisão) dos sujeitos que desestruturam o sistema, mesmo que a desestruturação do sistema pelos sujeitos seja uma resposta à violência do próprio sistema (Estado, mercado, justiça criminal).

A matéria teve quatro minutos e quarenta e cinco segundos, um tempo relativamente longo para os padrões de matérias de telejornal, que apresentou outras séries de arrastões como na praia de Copacabana e em outro condomínio na Zona Sul do Rio, além da fala do governador Pezão sobre o reforço no policiamento. Por meio de textos, sons e imagens, a notícia propõe o reforço no policiamento como solução, por exemplo, em "a informação é ainda pior, a polícia disse que nem tinha conhecimento de ocorrências ali na região". Como em destaque em outro recorte da mesma reportagem:

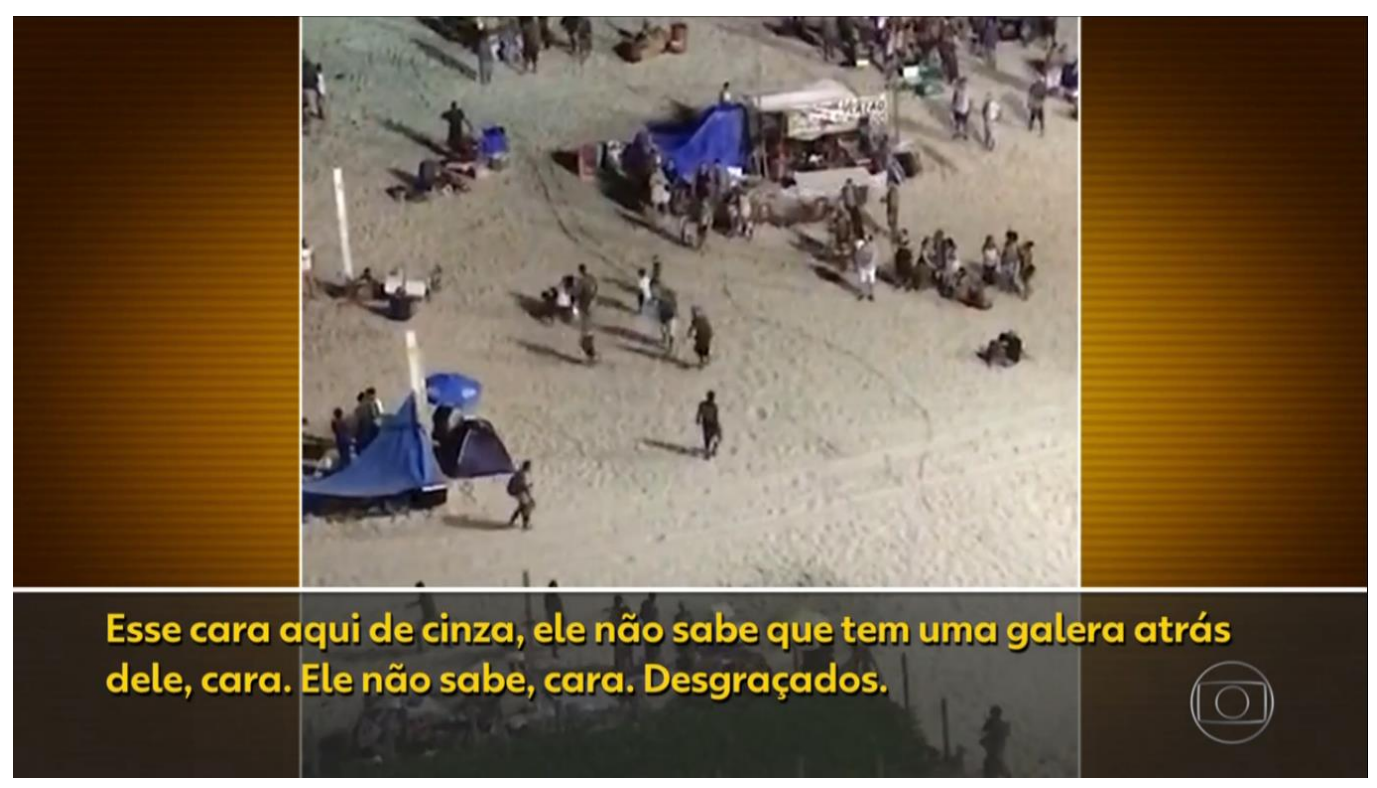

Figura 2 - Frame da matéria intitulada: Turistas são vítimas de arrastão em frente a um dos hotéis mais luxuosos Fonte: G1 PORTAL DE NOTÍCIAS (2018) 
Na imagem acima vários jovens negros correm para cima dos turistas e tomam bolsas e pertences pessoais. O vídeo foi realizado por moradores do prédio em frente à praia em que ocorreram os arrastões. Nesta parte da matéria a narração era intercalada pela narração do morador e autor do vídeo, o que isenta a repórter de categorizar, adjetivar ou emitir opinião sobre o caso. Pressupõe-se assim a imparcialidade no texto narrativo, porém o morador aqui executa o papel opinativo da matéria. Conforme aponta Bourdieu (1997), a seleção de umas imagens e não de outras, a seleção de uns discursos e não de outros, ditam o tom da reprodução do discurso e guiam o olhar do telespectador.

Da mesma forma segue outro objeto (link ${ }^{9}$ ) de mesmo sentido discursivo:

Apresentador: Uma confusão em Copacabana terminou em mais de noventa pessoas na delegacia, a maioria adolescentes, vamos agora falar com o Diego Haidar...

Repórter: Bom dia pra todo mundo, mais uma vez, confusão na saída da praia de Copacabana, a gente tem alguns vídeos que mandaram pra gente mostrando exatamente o que aconteceu. Um deles mostra um grupo de jovens correndo pela Nossa Senhora de Copacabana, tenta entrar pela porta da frente primeiramente, depois eles saem e tentam entrar pela porta de trás, tenta entrar no ônibus com ele já em movimento, depois tem até uma cadeira que é jogada contra a porta do ônibus, testemunhas que estavam por ali também contaram que menores furtaram alguns pedestres, também tentaram roubar produtos de uma vendedora ambulante e o cordão de uma outra pessoa. No final das contas foi a guarda municipal e a polícia militar pra lá. Foi todo mundo pra delegacia. Noventa e duas pessoas foram pra cidade da polícia, ainda bem que ali é grande, coube todo mundo. A polícia informou que era 78 adolescentes, 10 maiores de idade e 4 crianças. Um dos menores foi reconhecido pela vítima e acabou apreendido por ato infracional correspondente ao crime de furto. A polícia depois ligou para o conselho tutelar, tem que ligar para os pais também. E Fachel, este tipo de situação não é a primeira vez na saída de Copacabana. Dia de calor, apesar do inverno, dia de praia, precisa de uma atuação mais eficiente da polícia para evitar este tipo de coisa, porque é o banhista que fica à mercê de ser furtado, de ser roubado e o motorista também que coagido por esses grupos, Fachel.

Apresentador: Pois é Diego, a resposta é polícia na rua, é o que precisa. Tem que ter polícia preventiva na rua. (BOM DIA RJ, 2016).

\footnotetext{
${ }^{9}$ O link foi veiculado no dia 15 de setembro de 2016 no telejornal Bom dia RJ, transposta para o Portal de Notícias G1 da globo.com.
} 


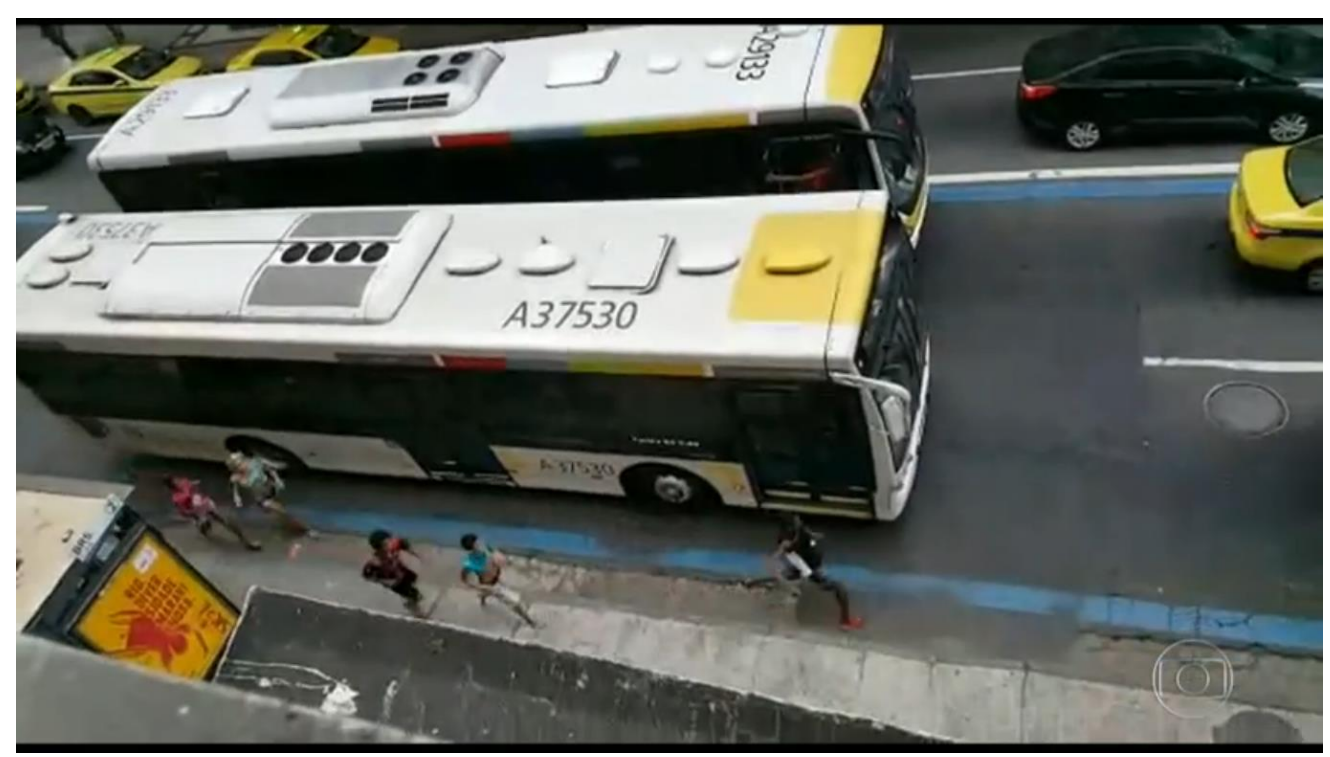

Figura 3 - Frame do material (link) intitulado: Tumulto em Copacabana tem 91 crianças e adolescentes apreendidas Fonte: G1 PORTAL DE NOTÍCIAS (2016)

No link acima, as imagens mostram crianças e adolescentes, em sua maioria pardas e negras, correndo na rua tentando entrar nos ônibus, enquanto o repórter narra sobre o arrastão e a falta de sossego dos banhistas nas praias da Zona Sul do Rio. A notícia destaca a perturbação e o medo dos assaltos como problema preponderante do bairro, isto é, o discurso predominante da classe média/alta que tem sua privacidade e segurança física em risco, em detrimento das questões sociais que levaram os menores (78 adolescentes e 4 crianças) para o crime. Além do pedido à policialização dos espaços urbanos como forma de atender aos interesses dominantes. O apresentador reforça: "polícia na rua, é o que precisa".

No artigo Notas provisórias sobre a percepção social do corpo (2014), Bourdieu aborda um ponto importante para a interpretação de ambos os materiais apresentados. Trata-se aqui do corpo como produto social, desta forma, a televisão sendo mais do que sons e textos, é imagem; e a pregnância destas imagens estigmatizam os corpos. O corpo é tratado aqui como linguagem, assim quando as imagens de jovens (mesmo que sem rostos, sua forma de vestir, de andar, de falar - uso ou não de gírias -, sua cor ou raça) são veiculadas na televisão dentro do mundo do crime, também estão implicadas neste contexto discursivo a venda de uma identidade social, nas palavras de Bourdieu:

O conjunto dos sinais distintivos que constituem o corpo percebido é o produto de uma fabricação propriamente cultural. Tendo como efeito distinguir os indivíduos - mais exatamente, os grupos - pelo grau de cultura ou, mais precisamente, pelo grau de distância com relação à 
natureza, [tal fabricação] parece encontrar seu fundamento na natureza, isto é, no gosto, [na medida em que] visa a exprimir uma natureza, porém cultivada. Não há sinais propriamente "físicos", e a cor e a espessura do batom, a configuração de uma mímica, a forma do rosto ou da boca, são imediatamente vistas como indícios de uma fisionomia "moral", socialmente caracterizada, quer dizer, [indícios] de estados de espírito "vulgares" ou "distintos", naturalmente "natureza" ou naturalmente "cultivados". (2014, p. 248).

Estas percepções sobre a identidade social do Outro também contribuem para a formação do mundo social, pois representam um padrão normativo sobre o corpo (perfil de mercado, por exemplo) que se revela como argumento de exclusão/inserção no sistema capitalista.

Os discursos também são compreendidos num campo de forças que corroboram para a manutenção do status quo, o pedido dos repórteres e apresentadores pelo policiamento como em, "precisa de uma atuação mais eficiente da polícia para evitar este tipo de coisa", e "em relação ao arrastão em Niterói a informação é ainda pior, a polícia disse que nem tinha conhecimento de ocorrências ali na região", reforçam a exigência da justiça criminal como instrumento de controle social. Pois, por meio da coerção e de um modelo disciplinar imposto, as ações punitivas contra os infratores servem de mecanismos apaziguadores dos conflitos sociais. Na medida em que as desigualdades sociais se acentuam juntamente com esta problemática, as medidas de coerção e punição também se fortificam, ou ainda, quando os conflitos sociais tentam desestruturar as estruturas sociais, vê-se o fortalecimento das ações/leis punitivas (FOUCAULT, 1997).

Em ambas as matérias, tanto os discursos como as imagens, justificam, naturalizam e legitimam as estruturas das classes sociais. De um lado, o apagamento das questões sociais por meio da reprodução dos discursos dominantes, de outro, a conformação dos sujeitos quanto às posições econômicas na hierarquia de classes que são fomentadas pelo poder simbólico da televisão, "Os símbolos são os instrumentos por excelência da 'integração social' [...], enquanto instrumentos de conhecimento e de comunicação [...] tornam possível o consensus acerca do sentido do mundo social" (BOURDIEU, 1989, p.10).

Também, o enfoque dos discursos dá ênfase na conformação da identidade social pautada na sociedade de classes. As narrativas dos jornais/telejornais são representativas, por isso contribuem para a formação de ideias, sentimentos e ações, portanto, das ideologias e das maneiras de organizar a sociedade. 


\section{Considerações finais}

Este trabalho teve por objetivo fazer uma reflexão sobre as matérias em telejornais quando estas constroem no imaginário coletivo o "inimigo", promovendo assim o ódio às minorias da sociedade. Não se trata de vilanizar os profissionais jornalistas, sabe-se que a área jornalística no mercado é um campo hostil e competitivo, e a mecânica de produção jornalística homogeneíza o noticiário, assim o jornalismo é "“[...] muito mais dependente das forças externas que todos os outros campos de produção cultural [...]. Ele depende muito diretamente da demanda, está sujeito à sanção do mercado, do plebiscito, talvez mais ainda do político" (BOURDIEU, 1997, p. 76). Assim se avalia que a técnica de produção da notícia elimina a criticidade, não há o que refletir antes de produzir ou mesmo o que se estudar quando o objetivo central é fazer notícias para serem vendidas. A reprodução dos discursos dominantes nestas notícias, que não conduzem à criticidade, fomenta o racismo e consegue carregar no tempo e no espaço a naturalização da desigualdade social. Além de apagar um legado colonialista violento, a permanência destes processos escravocratas nos moldes mais modernos inventa um imaginário social sobre as classes populares, independentemente da relação dessas pessoas com o crime ou não, mais do que informações, as notícias televisivas também são representativas.

Destaco três pontos importantes para justificar as influências do telejornal e os seus reflexos na sociedade, o efeito do real e a presunção da verdade (BOURDIEU, 1997), e a "redundância cotidiana (repetição)" com base em Foucault: "[A] notícia policial, por sua redundância cotidiana, torna aceitável o conjunto dos controles judiciários e policiais" (1997, p. 251). O efeito do real suscita sentimentos ao espectador capaz de provocar mobilizações (Bourdieu, 1997). A espetacularização da notícia consegue criar uma ideia de caos muito maior do que realmente é. O ódio despertado na dramatização dos fatos cega o debate sobre alternativas de combate à violência. O inimigo não é mais a violência, o inimigo é o Outro e a presunção da verdade confirma as ações punitivas e imediatistas incentivadas pelo consenso alienado do espectador.

\section{Referências}

BATISTA, Vera Malaguti. O medo na cidade do Rio de Janeiro: dois tempos de uma história. Rio de Janeiro: Revan, 2003. 
BOURDIEU, Pierre. Notas provisórias sobre a percepção social do corpo. ProPosições, Campinas, v. 25, n. 1, p. 247-256, abr. 2014. Disponível em:<http://www.scielo.br/scielo.php?script=sci_arttext\&pid=S01037307201400010001 $4 \& \operatorname{lng}=e n \& n r m=i s o>$. Acesso em: 28 jul. 2018.

BOURDIEU, Pierre. O poder simbólico. Lisboa: Difel, 1989.

BOURDIEU, Pierre. Sobre a televisão. Rio de Janeiro: Jorge Zahar, 1997.

BRASIL. MINISTÉRIO DA JUSTIÇA. Levantamento Nacional de informações Penitenciárias. Brasil: 2016. Disponível em: http://www.justica.gov.br/news/ha-726712-pessoas-presas-no-brasil/relatorio_2016_junho.pdf. Acesso em: 30 jul. 2018

FERNANDES, Florestan. A Integração do Negro na Sociedade de Classes. $3^{a}$ ed. São Paulo: Ática, 1978.

FOUCAULT, Michel. Vigiar e Punir: nascimento da prisão. Trad. Raquel Ramalhete. São Paulo: Vozes, 2009.

G1 PORTAL DE NOTÍCIAS. Turistas são vítimas de arrastão em frente a um dos hotéis mais luxuosos do Rio. Disponível em: <https://g1.globo.com/rj/rio-de-janeiro/carnaval/2018/noticia/turistassao-vitimas-de-arrastao-em-frente-a-um-dos-hoteis-mais-luxuosos-do-rio.ghtml>. Acesso em: 25 jul. 2018.

G1 PORTAL DE NOTÍCIAS. Tumulto em Copacabana tem 92 crianças e adolescentes apreendidas. Disponível em: http://g1.globo.com/rio-de-janeiro/noticia/2016/09/tumulto-emcopacabana-tem-92-criancas-e-adolescentes-apreendidas.html. Acesso em: 27 jul. 2018.

SOUZA, Jessé. A elite do atraso: da escravidão à Lava Jato. Rio de Janeiro: Leya, 2017.

SOUZA, Jessé. A Ralé Brasileira: quem é e como vive. Belo Horizonte: Editora UFMG, 2009. 


\section{Para citar essa obra:}

OLIVEIRA, Graziele Rodrigues. A violência urbana nas narrativas de telejornais e a construção do inimigo In: RUA [online]. Volume 25, número 2 - p. 353-549 - e-ISSN 2179-9911 npvembro/2019. Consultada no Portal Labeurb - Revista do Laboratório de Estudos Urbanos do Núcleo de Desenvolvimento da Criatividade.

http://www.labeurb.unicamp.br/rua/

Capa: Figura 2 - Frame da matéria intitulada: Turistas são vítimas de arrastão em frente a um dos hotéis mais luxuosos Fonte: G1 PORTAL DE NOTÍCIAS (2018)

\section{Laboratório de Estudos Urbanos - LABEURB}

Núcleo de Desenvolvimento da Criatividade - NUDECRI

Universidade Estadual de Campinas - UNICAMP

http://www.labeurb.unicamp.br/

Endereço:

LABEURB - LABORATÓRIO DE ESTUDOS URBANOS

UNICAMP/COCEN / NUDECRI

CAIXA POSTAL 6166

Campinas/SP - Brasil

CEP 13083-892

Fone/ Fax: (19) 3521-7900

Contato: http://www.labeurb.unicamp.br/contato 